PREPARED FOR THE U.S. DEPARTMENT OF ENERGY, UNDER CONTRACT DE-AC02-76CH03073

PPPL-3678

PPPL-3678

UC-70

The Use of MDSplus on NSTX at PPPL

by

W. Davis, P. Roney, T. Carroll, T. Gibney, and D. Mastrovito

March 2002

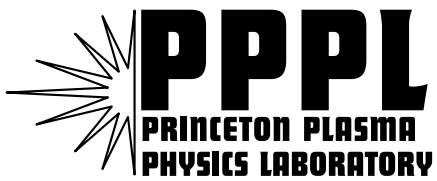

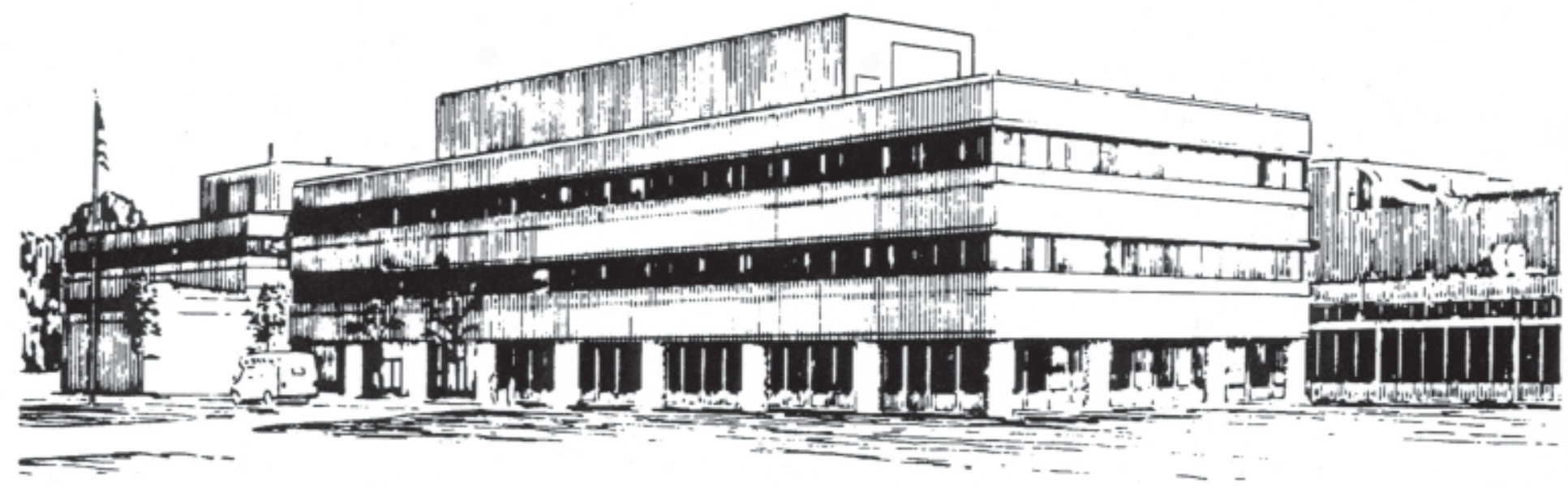

PRINCETON PLASMA PHYSICS LABORATORY PRINCETON UNIVERSITY, PRINCETON, NEW JERSEY 


\section{PPPL Reports Disclaimer}

This report was prepared as an account of work sponsored by an agency of the United States Government. Neither the United States Government nor any agency thereof, nor any of their employees, makes any warranty, express or implied, or assumes any legal liability or responsibility for the accuracy, completeness, or usefulness of any information, apparatus, product, or process disclosed, or represents that its use would not infringe privately owned rights. Reference herein to any specific commercial product, process, or service by trade name, trademark, manufacturer, or otherwise, does not necessarily constitute or imply its endorsement, recommendation, or favoring by the United States Government or any agency thereof. The views and opinions of authors expressed herein do not necessarily state or reflect those of the United States Government or any agency thereof.

\section{Availability}

This report is posted on the U.S. Department of Energy's Princeton Plasma Physics Laboratory Publications and Reports web site in Fiscal Year 2002. The home page for PPPL Reports and Publications is: http://www.pppl.gov/pub_report/

DOE and DOE Contractors can obtain copies of this report from:

U.S. Department of Energy

Office of Scientific and Technical Information

DOE Technical Information Services (DTIS)

P.O. Box 62

Oak Ridge, TN 37831

Telephone: (865) 576-8401

Fax: (865) 576-5728

Email: reports@adonis.osti.gov

This report is available to the general public from:

National Technical Information Service

U.S. Department of Commerce

5285 Port Royal Road

Springfield, VA 22161

Telephone: 1-800-553-6847 or

(703) 605-6000

Fax: (703) 321-8547

Internet: http://www.ntis.gov/ordering.htm 


\title{
The Use of MDSplus on NSTX at PPPL
}

\author{
W. Davis*, P. Roney, T. Carroll, T. Gibney, D. Mastrovito \\ Princeton Plasma Physics Laboratory, P.O. Box 451, Princeton, NJ 08543-0451
}

\begin{abstract}
The MDSplus data acquisition system has been used successfully since the 1999 startup of NSTX for control, data acquisition and analysis for diagnostic subsystems. For each plasma "shot" on NSTX about 75 MBs of data is acquired and loaded into MDSplus hierarchical data structures in 2-3 minutes. Physicists adapted to the MDSplus software tools with no real difficulty. Some locally developed tools are described. The support from the developers at MIT was timely and insightful. The use of MDSplus has resulted in a significant cost savings for NSTX.
\end{abstract}

Keywords: Data acquisition; Data visualization; Data management; MDSplus; NSTX

\section{Background}

The National Spherical Torus Experiment (Kaye, et al. [1]) (NSTX) began fusion experiments at the Princeton Plasma Physics Laboratory (PPPL) in February of 1999. During an experimental cycle, called a shot, a plasma is produced and 10's of megabytes of data are acquired from instruments in dozens of subsystems and transferred to a central computer system during the following 2-3 minutes.

MDSplus (Stillerman, et al. [2]) is a data acquisition and storage system used at several fusion facilities world-wide. The majority of the diagnostics on NSTX follow the "standard" MDSplus model, accessing CAMAC from a VMS computer, but the "national" aspect of NSTX requires that many pre-assembled diagnostics from collaborators be integrated as well. These typically come on "turn-key" PC systems and are written in C++, Visual Basic, or LabView. Additionally, NSTX data from an Experimental Physics and Industrial Control System (Sichta, et al. [3]) (EPICS) and from a VME-based real-time feedback control computer (Gates, et al. [4]) are stored in MDSplus. By storing all the data in MDSplus, standard tools can access any type of data with a minimum of specialized knowledge.

NSTX has a heterogeneous group of users. Some prefer the Unix operating system, some VMS, and some Windows. Some prefer Macintoshes as their workstation, some PC's, and others X-terminals. Some researchers can program effectively in a high-level computer language and others cannot. The majority of the scientists on NSTX are not full time on NSTX.

\footnotetext{
* Corresponding author. E-mail: bdavis@pppl.gov, Phone: (609)-243-2546, Fax: (609)-243-3086
} 


\section{Reasons for Choosing MDSplus}

Since it is usually less expensive to adapt existing software than to write it from scratch, we evaluated possible candidates. EPICS was chosen for NSTX's Distributed Control System, and an analogous system was needed for the shot cycle requirements. MDSplus was designed for shot cycle-based experiments similar to NSTX, whereas EPICS systems are generally used for experiments like large telescopes and accelerators. MDSplus supported most of the CAMAC modules from our \$6M inventory, and we would be able to add code for new modules.

\section{NSTX Computer Configuration}

As seen in Fig.1, a variety of computers are used at PPPL for NSTX.

In the middle of Fig. 1, a locally-written program receives notice of shot cycle events and invokes various components of MDSplus. All access to the diagnostic CAMAC highways is done on this VMS computer. Current shot data is written to a local RAID set, and is kept there for one week, after which time it is moved to the larger file systems shown in the lower right. On the left side of Fig 1, more sensitive applications, such as those controlling power supplies and vacuum valves, are run from computers behind a firewall. Data from the Control Systems, the real-time Feedback Control system, and the PC's (Mastrovito [5]) are stored into MDSplus trees after the shot. All but the EPICS systems use calls over TCP/IP to load their data into the trees.

The models of the major computers from Fig. 1 are listed in Table 1.

Users displaying and analyzing NSTX data typically run on Unix or VMS systems shared with other general users at PPPL. The MDSplus utilities, and routines written in IDL [6], look and feel the same on both platforms. PC's can also bring data from the MDSplus trees directly into applications written in languages that include IDL, LabView, Visual Basic, FORTRAN, C, and C++.

Within 3 minutes of the 1-second plasma "shot" on NSTX, 40 MBs are acquired from CAMAC crates on a VMS system, 22 MBs from UNIX systems, and 13 MBs from PC systems, and loaded into MDSplus hierarchical data structures, called trees. Raw data is stored in MDSplus trees with compression factors of 2.5-3.

30 to 40 local users and remote collaborators configure their software to display dozens of plots automatically on their X-windows as data becomes available. Data can be read from MDSplus trees into high-level language codes at $500 \mathrm{~KB} / \mathrm{s}$ on our general-use VMS systems, and about $20 \%$ slower on our Unix systems. All NSTX data stored in MDSplus is always on-line from VMS-served RAID disks. 


\section{Labor and Learning Costs}

While a basic MDSplus system can be brought up in a matter of weeks, local adaptations and extensions can take a widely varying amount of time. Though situations at different sites vary widely, we include our experience here as a possible rough guide to others.

MDSplus documentation is a work in progress, and is an acknowledged shortcoming at this time. It was sometimes helpful to examine MDSplus source code. The Tree Data Interface (TDI) language and Tree Control Language (TCL) are powerful tools included with MDSplus, but are documented only in a reference format. The best way to see how these are used is to find existing examples from other users

Software engineers worked 2.5 man-years prior to first plasma on NSTX, but less than half of this was involved with MDSplus. Several man months were spent learning various components of MDSplus in depth, and more learning occurred after operations began. A typical end user might just learn how to change a few data acquisition parameters in the Traverser tool and look at the data with a "Scope" set up by someone else. A user could reach this level of proficiency in a few hours. At the other extreme, a user may wish to develop complex algorithms in TDI, or in another language such as IDL, and this might take weeks or months to learn and perfect. The 30 primary, on-site physicists and 25 part-time physicists adapted to the MDSplus software tools with no real difficulty, but supporting these users requires one-quarter to one-half of a programmer's time during experimental operations.

It might take an experienced person a day to layout and create the initial data tree structure for a diagnostic. For the "Operations" tree of NSTX, which has 200 signals with different calibration algorithms, etc., it took weeks to write TCL code to generate the tree from a spreadsheet. It took about a man-month to design and implement the data management system for NSTX data (file locations, archiving, etc.). Four programmers (full-time equivalents) continue to support the use of MDSplus on NSTX; this includes assistance using the tools supplied with MDSplus as well as writing customized data acquisition setup and analysis programs. We wrote or modified MDSplus acquisition modules for half-a-dozen CAMAC modules. The first one took a man-month because the programmer only had modest experience with $\mathrm{C}$ and Motif. Subsequent modules took much less time.

\section{Locally-developed Tools}

Several legacy FORTRAN analysis codes have been converted with minimal effort to use MDSplus. Experiment-specific tools and routines in our user-written IDL libraries have been layered on top of MDSplus, and simplify the writing of specialized IDL codes. Data is automatically loaded into several MS-SQL databases between shots. Database tools are being converted from INGRES to MS-SQL. 
The X-windows-based program called Scope is supplied with MDSplus, and is powerful and efficient for any number of single $x-y$ traces per frame (the more fully-featured Java version (Manduchi, et al. [7]) is only used by a few NSTX collaborators on PC's). Some users need more elaborate or customized programs for particular applications. The features most requested over those of the original Scope program are the ability to overlay plots, plot in color, and plot two-dimensional data. Some users write their own display programs in IDL, but these often have limitations, such as color incompatibility with other applications, the inability to print easily, non-resizable graphics, bombs when used in unexpected ways, etc. We have tried to bring the General Atomics ReviewPlus (Schachter, et al. [8]) plotting tool into use at PPPL, but difficulties remain. Two other programs have evolved at PPPL for generic plotting of MDSplus data, FAS [9] and MDSw [10], but we are still looking for general plotting and analysis tools.

Some users are willing to give up some of the features and performance of the MDSplus tools and IDL codes for simpler point-and-click web pages to access their data. When they use the web, they don't need accounts, passwords, x-windows, knowledge of directories, color settings, etc. A few web-based utilities have been developed [11] at PPPL and have a rapidly growing and appreciative user base.

The tool shown in Fig. 2 allows researchers to understand this data much more easily and illustrates the power of using MDSplus and IDL for developing custom analysis programs. The common interface to data through MDSplus calls, and the availability of many IDL codes, facilitated the writing of this utility in a single day. Plots on the right are profiles, with the minor radius of the plasma as their horizontal axis, while the plots on the left are versus time. Images from the LANL Fast Camera are animated in the lower left. The profile at a particular time is drawn in black, while others are drawn in a lighter color. As the VCR-like controls advance the animation, the dashed lines on the plots on the left move to correspond to that time in the trace.

\section{Next Steps}

We plan to organize informational messages better, such as relevant CAMAC or timing errors, and provide automatic notification (and the ability to turn it off!). Several automatic programs run after the shot to analyze and display data, but errors are only written to a log file, and often go unnoticed. While MDSplus events are a powerful and convenient way to notify software tasks, it is not always evident which events are being declared, and for what purpose. It would help us diagnose some problems if the time and source of event declaration were easily available.

We plan to use PCI-based hardware for data acquisition for new diagnostics when possible, rather than CAMAC.

\section{Summary}


MDSplus has been used successfully on NSTX for diagnostic data acquisition and the storage of all NSTX data. The turnkey aspects of MDSplus were found to be logical and reliable. Adding new features, such as support for new CAMAC modules, or including data from other systems was more difficult, but not unreasonably so. The support from the developers at MIT, needed especially with the intricacies of TCL and TDI, has been timely and insightful. The use of MDSplus on NSTX has saved man-years of labor, and has provided a sound and powerful system that can grow with our requirements, and those of the fusion community.

\section{Acknowledgements}

The authors thank G. Oliaro and S. Davis for guidance in designing the use of MDSplus on NSTX, and P. Sichta for work on communication with the EPICS system. Many thanks to T. Fredian and J. Stillerman from MIT for support with MDSplus issues. This work was supported by DOE Contract DE-AC02-CHO3073.

\section{References}

[1] Kaye et al., The Physics Design of the National Spherical Torus Experiment. Fusion Technology, 36, July 1999, p. 16, or http://nstx.pppl.gov/index.shtml.

[2] J.A. Stillerman, T.W. Fredian, K.A. Klare, G. Manduchi, MDSplus Data Acquisition System. Review of Scientific Instruments, 68 (1) January, 1997, p. 939.

[3] P. Sichta, J. Dong, Startup of the Experimental Physics Industrial Control System at NSTX, $18^{\text {th }}$ Symposium on Fusion Engineering, Albuquerque, NM (1999).

[4] D. A. Gates, D. Mueller, C. Neumeyer and J. R. Ferron, Control System Development plan for the NSTX, IEEE RT99 Conference (June, 1999), IEEE Trans. Nucl. Sci., 1999.

[5] D. Mastrovito, Integration of Windows Applications with MDSplus Data Acquisition On NSTX at PPPL. Presented at the 3rd IAEA TCM on Control, Data Acquisition, and Remote Participation for Fusion Research, Padova, Italy (2001), Fusion Eng. Des., in press.

[6] IDL - The Interactive Data Language http://www.rsinc.com/idl/

[7] G. Manduchi, C. Taliercio, A. Luchetta, The Java interface of MDSplus: towards a unified approach for local and remote data access, Fusion Engineering Design 48 (2000) 163-170.

[8] J. Schachter, Q. Peng, D.P. Schissel, Data analysis software tools for enhanced collaboration at the DIII-D National Fusion Facility, Fusion Engineering Design 48 (2000) 91-98. 
[9] FAS User's Guide, http://nstx.pppl.gov/nstx/Software/fas/index.html.

[10] MDSw - An IDL widget for plotting MDSplus data, http://w3.pppl.gov/ bdavis/pppl_idl_routines.html.

[11] Web-based tools for NSTX, http://nstx.pppl.gov/nstx/Software/WebTools/ 


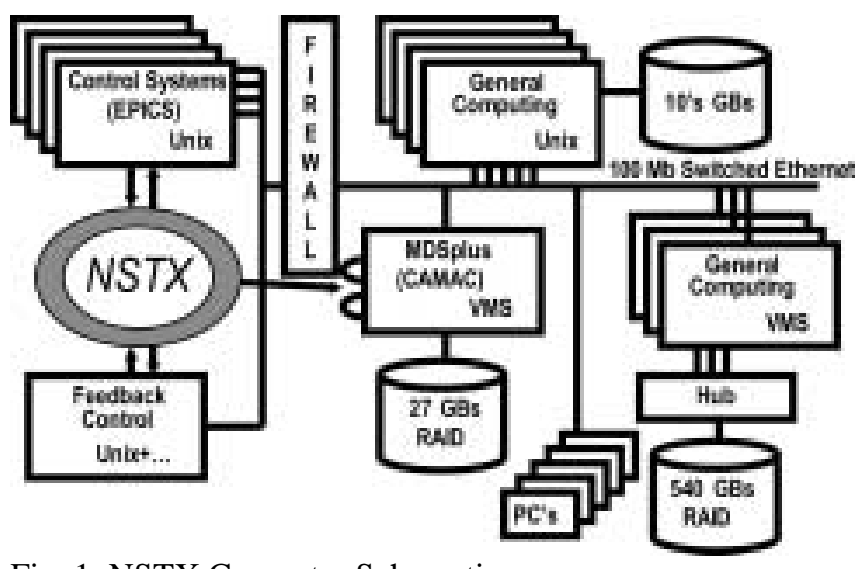

Fig. 1. NSTX Computer Schematic

\begin{tabular}{|l|l|c|r|r|}
\hline OS & Model & $\begin{array}{c}\# \\
\text { CPU }\end{array}$ & MHz & $\begin{array}{c}\text { MBs } \\
\text { RAM }\end{array}$ \\
\hline VMS & DS20E & 2 & 667 & 3500 \\
\hline VMS & AlphaServer 800 & 1 & 500 & 1000 \\
\hline VMS & Alpha 2100A 4/275 & 3 & 275 & 768 \\
\hline VMS & Alpha 2100 4/275 & 3 & 275 & 500 \\
\hline Solaris & UltraSPARC-II & 4 & 400 & 2000 \\
\hline Solaris & UltraSPARC-II & 2 & 400 & 1500 \\
\hline Solaris & (2) Sparc Ultra 30 & 1 & 300 & 768 \\
\hline
\end{tabular}

Table 1. The Major PPPL Computers used on NSTX.

File

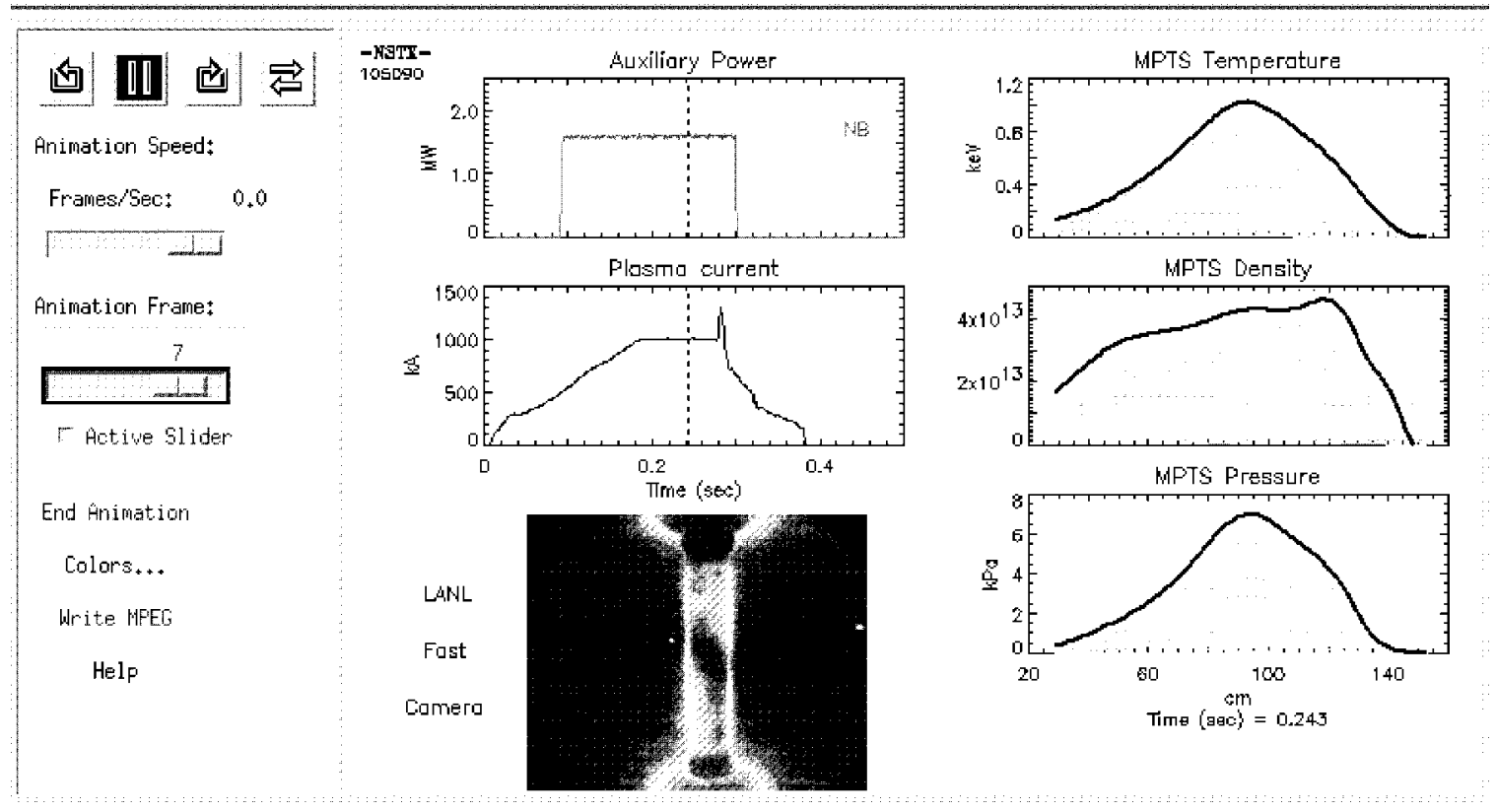

Fig. 2. IDL Widget for animating various types of MDSplus data. 


\section{External Distribution}

Plasma Research Laboratory, Australian National University, Australia

Professor I.R. J ones, Flinders University, Australia

Professor J oão Canalle, Instituto de Fisica DEQ/IF - UERJ , Brazil

Mr. Gerson O. Ludwig, Instituto Nacional de Pesquisas, Brazil

Dr. P.H. Sakanaka, Instituto Fisica, Brazil

The Librarian, Culham Laboratory, England

Library, R61, Rutherford Appleton Laboratory, England

Mrs. S.A. Hutchinson, JET Library, England

Professor M.N. Bussac, Ecole Polytechnique, France

Librarian, Max-Planck-Institut für Plasmaphysik, Germany

J olan Moldvai, Reports Library, MTA KFKI-ATKI, Hungary

Dr. P. Kaw, Institute for Plasma Research, India

Ms. P.J . Pathak, Librarian, Insitute for Plasma Research, India

Ms. Clelia De Palo, Associazione EURATOM-ENEA, I taly

Dr. G. Grosso, Instituto di Fisica del Plasma, Italy

Librarian, Naka Fusion Research Establishment, J AERI, J apan

Library, Plasma Physics Laboratory, Kyoto University, J apan

Research Information Center, National Institute for Fusion Science, J apan

Dr. O. Mitarai, Kyushu Tokai University, J apan

Library, Academia Sinica, Institute of Plasma Physics, People's Republic of China

Shih-Tung Tsai, Institute of Physics, Chinese Academy of Sciences, People's Republic of China

Dr. S. Mirnov, TRINITI, Troitsk, Russian Federation, Russia

Dr. V.S. Strelkov, Kurchatov Institute, Russian Federation, Russia

Professor Peter Lukac, Katedra Fyziky Plazmy MFF UK, Mlynska dolina F-2, Komenskeho Univerzita, SK-842 15 Bratislava, Slovakia

Dr. G.S. Lee, Korea Basic Science Institute, South Korea

Mr. Dennis Bruggink, Fusion Library, University of Wisconsin, USA

Institute for Plasma Research, University of Maryland, USA

Librarian, Fusion Energy Division, Oak Ridge National Laboratory, USA

Librarian, Institute of Fusion Studies, University of Texas, USA

Librarian, Magnetic Fusion Program, Lawrence Livermore National Laboratory, USA

Library, General Atomics, USA

Plasma Physics Group, Fusion Energy Research Program, University of California at San Diego, USA

Plasma Physics Library, Columbia University, USA

Alkesh Punjabi, Center for Fusion Research and Training, Hampton University, USA

Dr. W.M. Stacey, Fusion Research Center, Georgia Institute of Technology, USA

Dr. J ohn Willis, U.S. Department of Energy, Office of Fusion Energy Sciences, USA

Mr. Paul H. Wright, Indianapolis, Indiana, USA 
The Princeton Plasma Physics Laboratory is operated by Princeton University under contract with the U.S. Department of Energy.

\author{
Information Services \\ Princeton Plasma Physics Laboratory \\ P.O. Box 451 \\ Princeton, NJ 08543
}

Phone: 609-243-2750

Fax: 609-243-2751

e-mail: pppl_info@pppl.gov

Internet Address: http://www.pppl.gov 